\title{
Study on Synergies of Fly Ash with Multiwall Carbon Nanotubes in Manufacturing Fire Retardant Epoxy Nanocomposite
}

\author{
Tuan Anh Nguyen (iD) and Quang Tung Nguyen \\ Faculty of Chemical Technology, Hanoi University of Industry, No. 298 Cau Dien, North District Tu Liem, Hanoi, Vietnam \\ Correspondence should be addressed to Tuan Anh Nguyen; anhnt@haui.edu.vn
}

Received 25 March 2020; Revised 27 June 2020; Accepted 18 July 2020; Published 8 August 2020

Guest Editor: Carlos Alves

Copyright ( $) 2020$ Tuan Anh Nguyen and Quang Tung Nguyen. This is an open access article distributed under the Creative Commons Attribution License, which permits unrestricted use, distribution, and reproduction in any medium, provided the original work is properly cited.

In this study, fly ash (FA) and multiwalled carbon nanotubes (MWCNTs) were used to make environmentally friendly nanocomposites, which have high fire retardant properties and high mechanical properties. Industrial waste such as fly ash has become a major concern during the treatment of environmental pollution. MWCNTs were used in this experiment to enhance the flame retardant properties and mechanical properties of materials with fly ash additives. MWCNTs content $(0.03,0.04$, and 0.05 wt.\%) and fly ash content (30,40, and $50 \mathrm{wt} . \%)$ were studied for three different levels. The flame retardancy of the material is significantly improved by the addition of fly ash/MWCNTs at different rates, especially at $0.04 \mathrm{wt}$ \% MWCNTs and $40 \mathrm{wt}$. \% fly ash with LOI at $26.8 \%$. Regarding mechanical properties, tensile strength increases as fly ash/MWCNTs increase, up to a critical point. On the other hand, the compressive strength of composite increases continuously as fly ash/MWCNTs increase. Scanning electron microscopy (SEM) was used to observe the morphology of fly ash and MWCNTs as well as its distribution in the matrix. This will help analyze the influence of the effectiveness of the combination of fly ash and MWCNTs to the flame retardancy and mechanical properties of fly ash/MWCNTs/epoxy nanocomposites.

\section{Introduction}

Epoxy resins have high adhesion characteristics with many reinforcements, good chemical resistance and corrosion resistance, and superior electrical properties; they are widely used in various industrial fields such as coatings, bearing structures, adhesives, and composite materials. However, one of the main disadvantages of epoxy resin is its inherent flammability, which has limited its application in many areas because the safety is considered. So this is an important issue to improve flame retardant of epoxy resin.

Fly ash (FA) is an industrial solid waste produced by coal power plants. The disposal of fly ash waste by landfill at landfills has polluted the environment, which is a major concern about environmental pollution [1]. FA is one of the additives used in composites, making applications of materials in different fields. In recent times, fly ash has been studied by many scientists around the world as an additive for polymers. In order to expand the application of fly ash and diversify products [2], Sroka et al. studied the use of fly ash in the manufacture of thermal insulating materials [3]. Sroka et al. also studied fly ash denaturation by [3- (2aminoethylamino) propyl] trimethoxysilane. The results show that the mechanical properties have been significantly improved compared to the unmodified fly ash. The work has demonstrated the use of modified fly ash as an additive to make epoxy composite materials that can be applied in the field of civil electricity [4]. Research on the effect of fly ash on the mechanical properties of epoxy composites shows that increasing the mass of fly ash results in reduced tensile strength and increased flexural and compressive strength [5]. In particular, the recent studies published by scientists are about the use of fly ash in manufacturing materials with high fire resistance and, at the same time, the mechanical properties remain stable; the content of fly ash used for the study was 5, 10, and 20 wt.\% [6]. V. C. Divya and his colleagues have conducted research on making composite materials based on polyethylene based plastic using fly ash 
and MWCNTs. The results showed that with 0.2 wt. \% MWCNTs, 20 wt. \% fly ash gave the best fire resistance [7]. M. Soyama et al. also studied the flame retardant properties of polycarbonate composites with $25 \mathrm{wt} \%$ resulting in samples with a high flame retardant [8]. Sim et al. [9] studied fly ash at levels of 10,30, and $50 \mathrm{wt} \%$, showing that the compressive strength increases with increasing fly ash content. Several other studies are about the effects of aging on the mechanical properties of epoxy composites with 20 wt.\% [10]. In addition, fly ash is also used to make epoxy composites with insulating properties, studied by Pham Thi Huong [11]. Fly ash is also used to make geopolymer; however, to improve some mechanical properties such as tensile strength and bending strength, some scientists have added nanoadditives such as MWCNTs to enhance some of the degraded durability in the desired green concrete production [12-14]. This is the study on flame retardant properties and mechanical properties of epoxy nanocomposites materials in the presence of fly ash additives and reinforced by MWCNTs. During the study of using fly ash additives to make composites, some mechanical strength was reduced, hence, this research sought to overcome the above limitation by adding nanoadditives, namely, MWCNTs.

(i) Curing agent: epoxy resin is converted into solid and insoluble three-dimensional networks by curing with cross-linkers. This study collected amine function curing agent diethylenetriamine of Dow Chemical Company to research. Diethylenetriamine: $\mathrm{H}_{2} \mathrm{~N}\left(\mathrm{CH}_{2}\right)_{2} \mathrm{NH}\left(\mathrm{CH}_{2}\right)_{2} \mathrm{NH}_{2}$ (DETA), density $0.953 \mathrm{~g} / \mathrm{cm}^{3}$ at $20^{\circ} \mathrm{C}$, boiling point $207^{\circ} \mathrm{C}$, Mw: $103.2 \mathrm{gmol}^{-1}$, and epoxy curing reaction with DETA (see Figure 1).

(ii) $\mathrm{HCl}, \mathrm{NaOH}$ of Dow Chemicals (USA).

(iii) Fly ash is supplied from Song Da 12- Cao Cuong Joint Stock Company (Vietnam). This is real; the product is extracted from waste ash and ash from Pha Lai Thermal Power Plant (Vietnam). It consists of a solid mixture and the spherical particles have different sizes (from $1 \mu \mathrm{m}$ to $100 \mu \mathrm{m}$, average size: $28 \mu \mathrm{m})$.

(iv) Multiwall carbon nanotubes (MWCNTs) of Showa Denko (Japan) are synthesized by catalyst deposition method. MWCNTs have an average diameter of $40-45 \mathrm{~nm}$, an average length of $3 \mu \mathrm{m}$, and a density of $0.08 \mathrm{~g} / \mathrm{cm}^{3}$.

\section{Materials and Methods}

\subsection{Materials}

(i) Epoxy Epikote 240 (EP) resin of Shell Chemicals (USA) (see Table 1)

\subsection{Methods}

2.2.1. Sample Preparation. The Fly ash was prepared according to Table 2. Fly ash (30, 40, and $50 \mathrm{wt} \%)$ and MWCNT $(0.03,0.04$, and 0.05 wt $\%)$ were dispersed in epoxy Epikote 240 resin, stirred at $3000 \mathrm{rpm}$ for $8 \mathrm{~h}$
(HS-100T, WiseStir, Korea). In order to break up the MWCNT bundles and disperse the additives, the ultrasonic vibration uses an ultrasonic bath (Elmasonic S300 $\mathrm{H}, 37 \mathrm{kHz}$, Germany) for $6 \mathrm{~h}, 65^{\circ} \mathrm{C}$. After the mixtures were homogenously mixed, the curing agent DETA (amount of curing agent was calculated by epoxy content of epoxy resin and stirred for $15 \mathrm{~min}$ at $200 \mathrm{rpm} / \mathrm{min}$ ) was added and the mixtures were moulded for curing. The mould was coated with a uniform thin film of silicone, a releasing agent for easy removal of cured specimen. The samples were cured at room temperature for about $24 \mathrm{~h}$ and further cured at $80^{\circ} \mathrm{C}$ in the laboratory oven for $3 \mathrm{~h}$. Then, the samples were removed from the mould and, after 7 days, the mixture was analyzed and mechanical properties were measured.

\subsubsection{Characterizations}

\section{(1) Mechanical Properties}

(i) Tensile strength is determined according to ISO $527-1993$ on INSTRON $5582-100 \mathrm{kN}$ (United States) with a pulling speed of $5 \mathrm{~mm} / \mathrm{min}$, temperature of $25^{\circ} \mathrm{C}$, and humidity of $75 \%$.

(ii) Flexural strength is determined according to ISO 178-1993 standard on INSTRON $5582-100 \mathrm{kN}$ (United States) with bending speed of $5 \mathrm{~mm} / \mathrm{min}$, temperature of $25^{\circ} \mathrm{C}$, and of humidity $75 \%$.

(iii) Compressive strength is determined according to ISO 604-1993 on INSTRON 5582-100 kN (United States), compression speed of $5 \mathrm{~mm} / \mathrm{min}$, and temperature of $25^{\circ} \mathrm{C}$.

(iv) Izod impact resistance is determined according to ASTM D265 on Tinius Olsen (USA), measured at Polymer Materials Research Center, Hanoi University of Science \& Technology (HUST).

\section{(2) Flame Retardants Properties}

(i) Limit oxygen index (LOI) according to ASTM D2863-12 and JIS K720 (Japan): the bars used for the test are $150 \times 6.5 \times 3 \mathrm{~mm}^{3}$.

(ii) Horizontal combustion tests (UL-94HB): the test piece of the standard bar must be $125 \pm 5 \mathrm{~mm}$ long, $13.0 \pm 0.5 \mathrm{~mm}$ wide, and supplied in minimum thickness and thickness of $3.0(-0.0+0.2) \mathrm{mm}$ (ASTM D635-12).

(iii) Fire resistance: equipment, specially designed for fire and flame retardant of thermoplastic, thermosetting, hard, and thin laminates, designed and engineered to meet the following standards: ASTM D 757; specimen size of $3.17 \times 12.7 \times 121 \mathrm{~mm}^{3}$; and maximum temperature of $950^{\circ} \mathrm{C}$, measured at Polymer Materials Research Center, Hanoi University of Science \& Technology (HUST).

(3) Method of Determining the Structural Morphology of Materials 


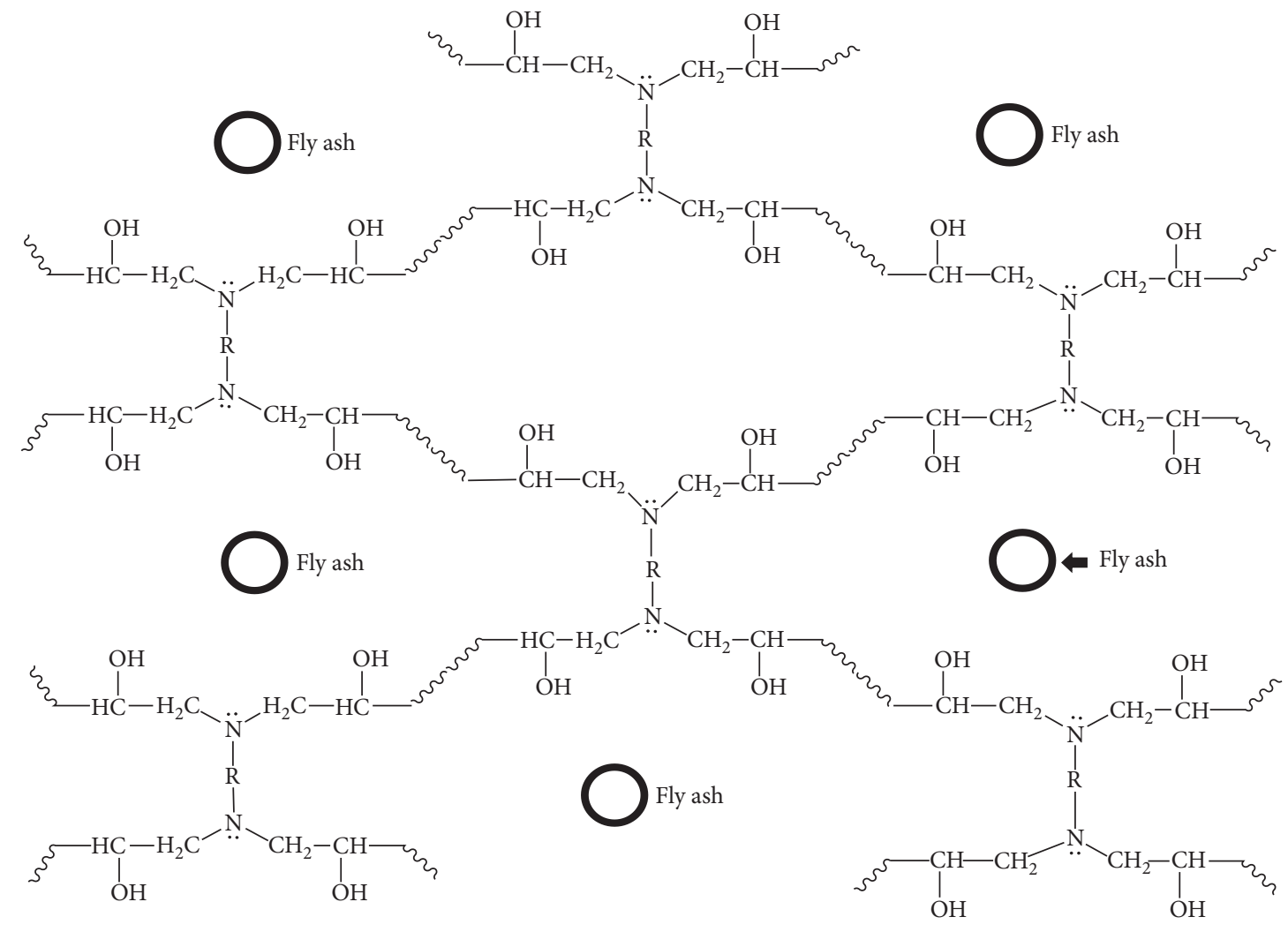

FIGURE 1: Images of fly ash particles alternating between epoxy molecules after plastic curing [15].

TABle 1: Specification of epoxy Epikote 240 resin.

\begin{tabular}{lccc}
\hline Property & Test method & Unit & Value \\
\hline Epoxy group content & SMS 2026 & $\mathrm{mmol} / \mathrm{kg}$ & $5100-5400$ \\
Epoxy molar mass* & & $\mathrm{g}$ & $185-196$ \\
Viscosity at $25^{\circ} \mathrm{C}$ & ASTM D445 & Pa.s** & $0.7-1.1$ \\
Colour & ASTM D1209 & Pt-Co & $200 \mathrm{max}$ \\
Density at $25^{\circ} \mathrm{C}$ & ASTM D4052 & $\mathrm{kg} / \mathrm{L}$ & 1.12 \\
\hline
\end{tabular}

* Number of grams of resin containing 1g equivalent of epoxide (weight per equivalent, (WPE) is an alternative term). ${ }^{* *} 1$ Pa.s $=10$ poise.

TABle 2: Taguchi orthogonal array of designed experiments based on the coded levels.

\begin{tabular}{lccc}
\hline Trial & Fly ash (wt\%) & MWCNTs content (wt\%) & Sample code \\
\hline 1 & 0 & 0.03 & FA01 \\
2 & 30 & 0 & FA02 \\
3 & 30 & 0.03 & FAST1 \\
4 & 40 & 0.03 & FAST2 \\
5 & 50 & 0.03 & FAST3 \\
6 & 30 & 0.04 & FAST4 \\
7 & 40 & 0.04 & FAST5 \\
8 & 50 & 0.04 & FAST6 \\
9 & 30 & 0.05 & FAST7 \\
10 & 40 & 0.05 & FAST8 \\
11 & 50 & 0.05 & FAST9 \\
\hline
\end{tabular}

(i) The morphology of the samples was carried out by scanning electron microscope (SEM, S4800-NIHE, $10.0 \mathrm{kV}$, Japan).

\section{Results and Discussion}

3.1. Morphology of Nanocomposites. The fractured surface morphology of epoxy and composites is shown in Figure 2, with 40 wt.\%

Images show a separation between fly ash particles (orbs) and epoxy resin. This phenomenon shows a poor communication link between epoxy and fly ash.

Mechanical stirring method combined with ultrasonic vibration was selected to conduct mixing in the fabrication of samples. The degree distribution observed by SEM image is shown in Figure 3. Figure 3 shows the uniformly distributed fly ash particles and clearly shows good wetting and bonding well with epoxy substrates. The evidence is that after the material is broken, the fly ash particles are still retained on the broken surface and the epoxy resin surrounds the particle.

The structural morphology image (Figure 4(a)) shows that fly ash particles are strongly bonded with the epoxy resin. However, there are still small (small) gaps around the fly ash element.

On the other hand, from another perspective, when there is external force, a part of fly ash is broken (red arrow), but it has not been removed from the substrate (Figure 4(b)).

In that gas, MWCNTs are also distributed evenly (the position of the arrows), there is no phenomenon of clustering and agglomeration, showing the good compatibility of MWCNTs-fly ash-epoxy combination. From the results of SEM image, fly ash was dispersed quite well and wet well, 

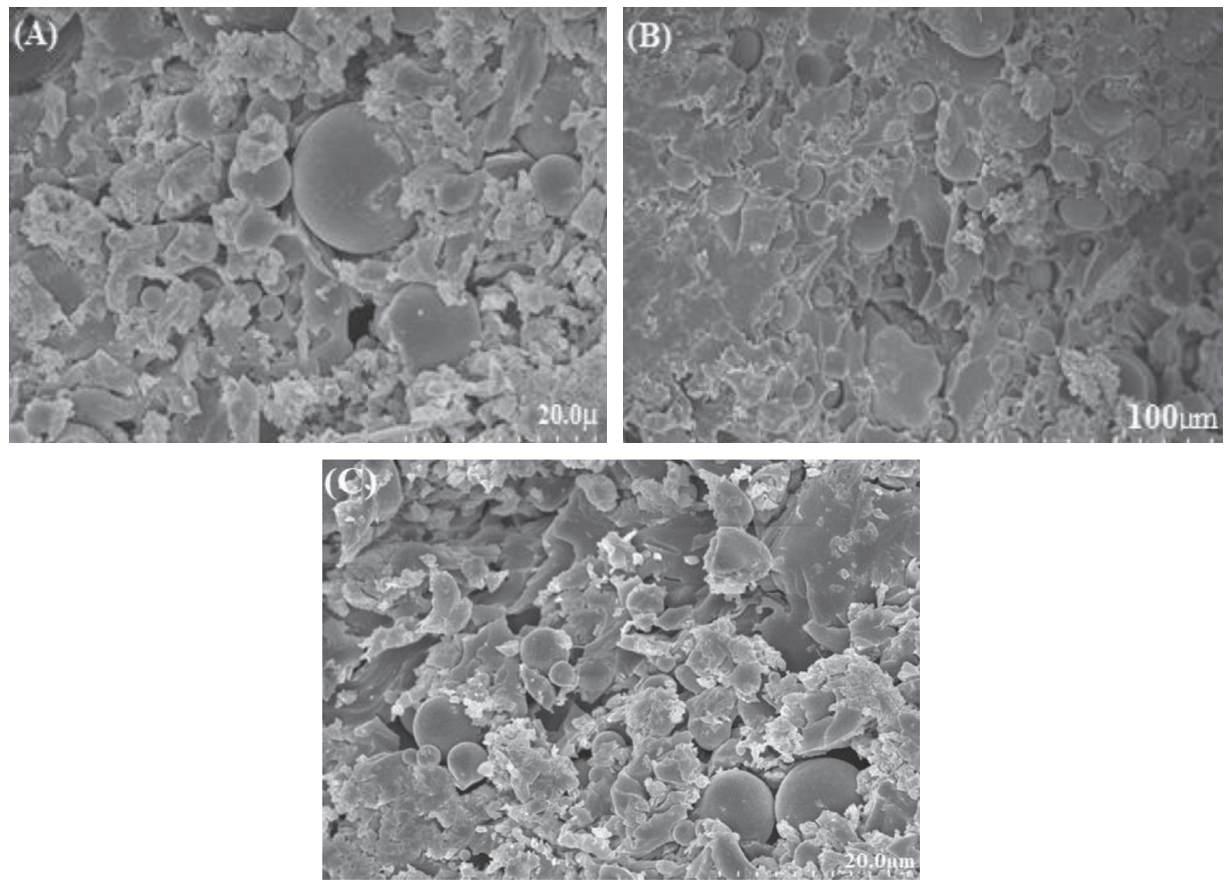

FiguRE 2: SEM image of epoxy composite material/fly ash: fly ash 40 wt.\% ((a), (b)).
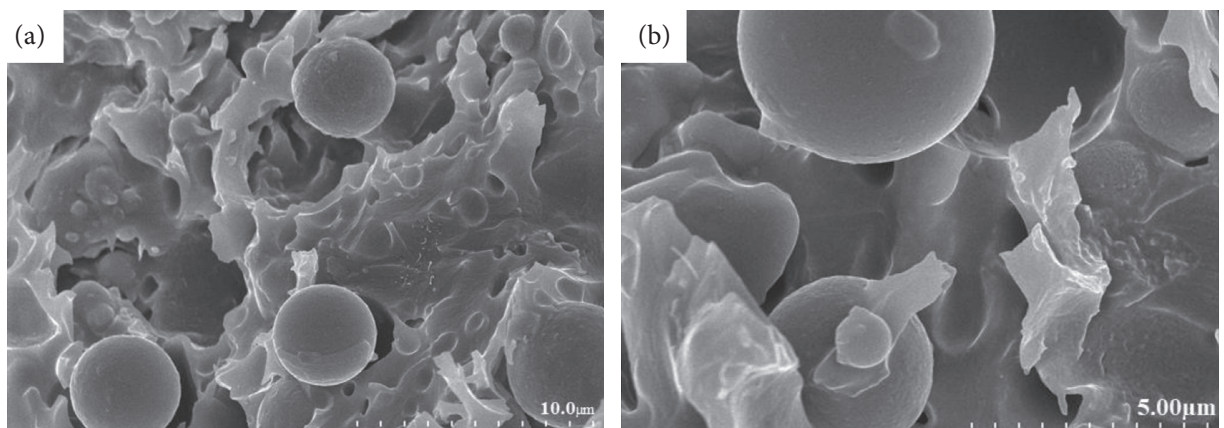

Figure 3: SEM images of nanocomposites: 30 wt.\% fly ash/0.03 wt.\% MWCNTs/epoxy ((a), (b)).

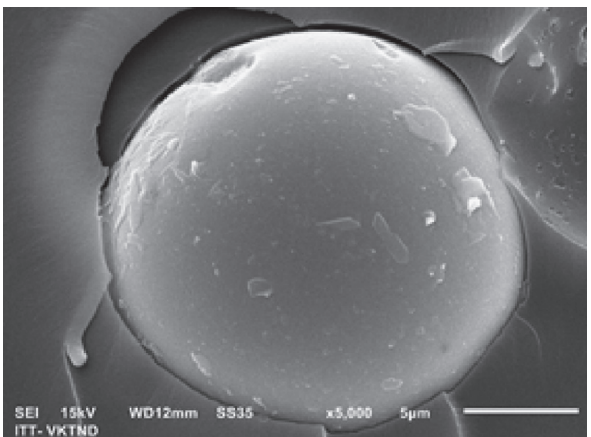

(a)

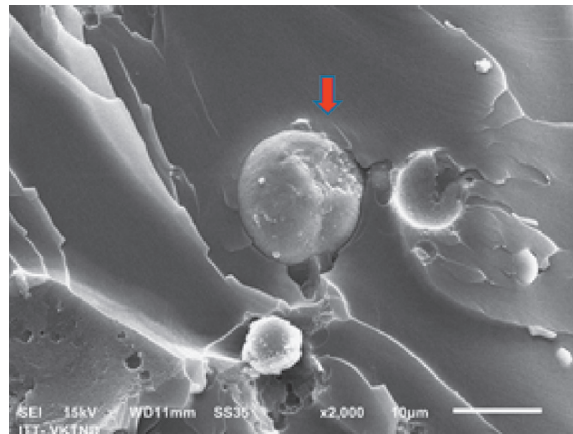

(b)

Figure 4: SEM images of nanocomposites: 40 wt.\% fly ash/0.04 wt.\% MWCNTs/epoxy ((a), (b)).

there were no holes and fly ash particles adhered well to epoxy E 240, broken surface of smooth material (see Figure 5).
The scanning electron microscope was used to observe the dispersion/fracture morphology of the MWCNT/epoxy resin/fly ash composites with higher resolution. SEM 


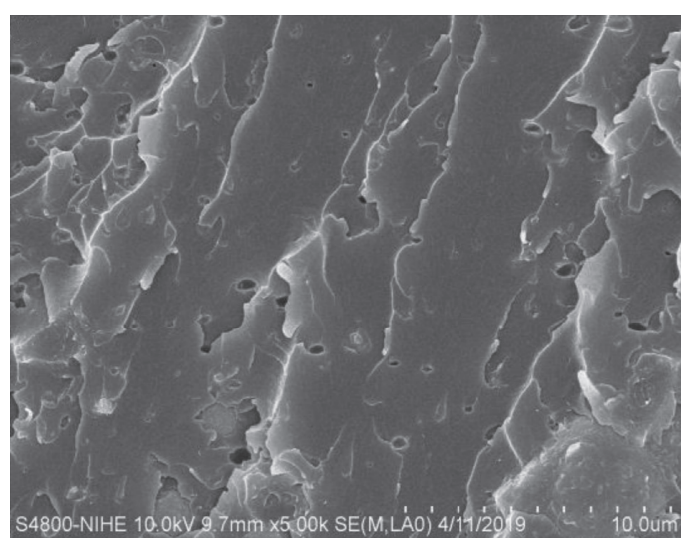

(a)

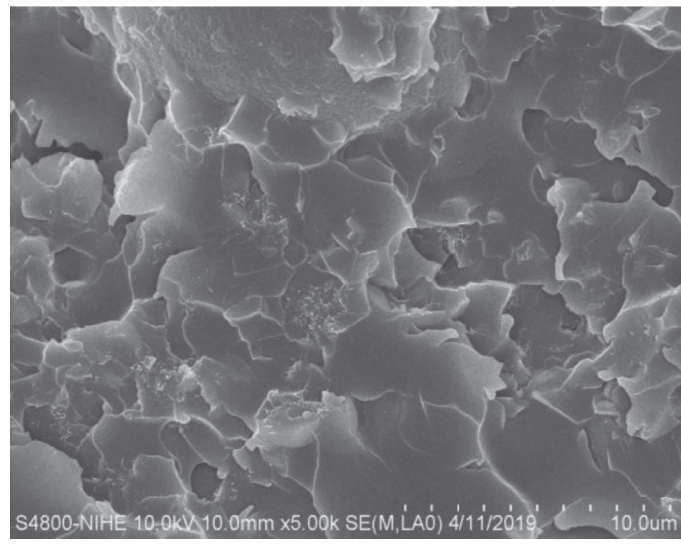

(c)

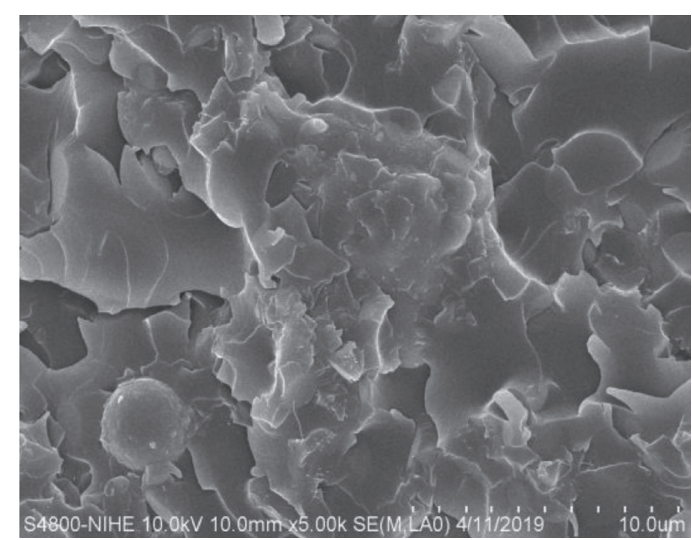

(b)

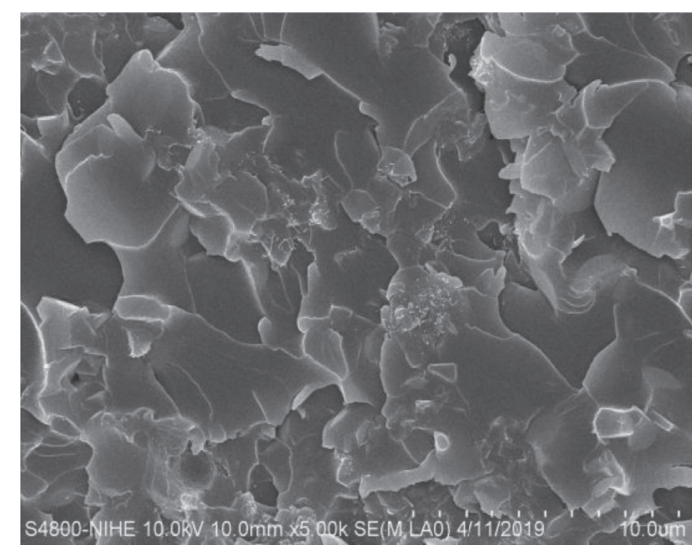

(d)

Figure 5: SEM images of nanocomposites fly ash/MWCNTs/epoxy: (a) 30 wt.\% fly ash/0.03 wt.\% MWCNTs/epoxy; (b) 40 wt.\% fly ash/0.03 wt.\% MWCNTs/epoxy; (c) 40 wt.\% fly ash/0.04 wt.\% MWCNTs/epoxy; and (d) 40 wt.\% fly ash/0.05 wt.\% MWCNTs/epoxy.

micrograph shows the dispersion (Figures 6(a) and 6(b)) and agglomeration (Figure 6(c)) of MWCNT in epoxy resin.

Meanwhile, the MWCNTs are evenly distributed and crept into the area interspersed with fly ash; there is no clustering and agglomeration phenomenon, which shows the good compatibility of the MWCNTs-fly ash-epoxy E240 combination, especially at manufacturing rates: $0.04 \%$ MWCNTs $/ 40 \%$ fly ash (see Figures $7(\mathrm{a})$ and $7(\mathrm{~b})$ ).

This can be explained that at the mixing level of $40 \%$ by weight of fly ash and $0.04 \%$ by weight of MWCNTs, the material achieves high compatibility, the condensed structure is suitable for mechanical properties and fire resistance.

3.2. Mechanical Properties. The fractured surface is very rough which proves that the material has a high strength, so the destruction is difficult. MWCNTs play an important role in limiting the development of fractures (Table 3) and require great force.

The mechanical strength of nanocomposite materials (tensile strength, flexural strength, compressive strength, and Izod impact resistance) is shown in Table 3.

The mechanical strength of the sample has been improved at the mixing ratio of $40 \%$ by weight of fly ash and
$0.04 \%$ by weight of MWCNTs. In other proportions, the mechanical properties tend to decrease, possibly due to the limited dispersion ability, thus reducing the mechanical strength.

From the research, the results show that tensile strength, flexural strength, and impact strength tend to decrease as fly ash content increases while compressive strength increases. However, when adding nanoadditive MWCNTs, the mechanical strength above has been significantly improved. The research results show that at the rate of 40 wt.\% fly ash combined with 0.04 wt.\% MWCNTs, the mechanical durability is at a high level suitable to meet the needs of manufacturing applied products. This can be explained as follows: at the content of $40 \mathrm{wt} \%$ fly ash, $0.04 \mathrm{wt} . \%$ MWCNTs achieved the best compatibility, when increasing the content of fly ash and MWCNTs, the viscosity increased sharply and, hence, the properties of the material were reduced, resulting in insufficient base resin to cover the fly ash particles. Therefore, a part of fly ash additive does not absorb enough plastic, causing defects in the material to reduce durability.

Under the effect of stress, the epoxy material will show cracks in the most critical areas and those cracks will grow, in the presence of MWCNTs which are dispersed evenly with nanometer size in epoxy; cracks can be effectively 


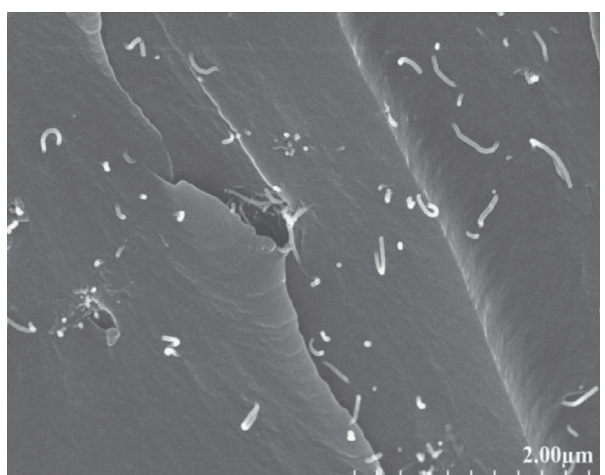

(a)

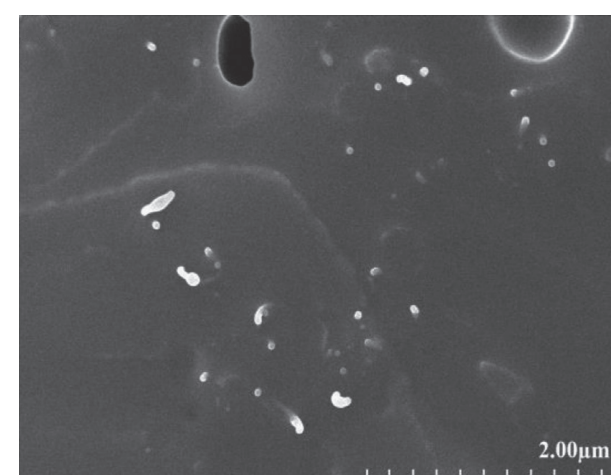

(b)

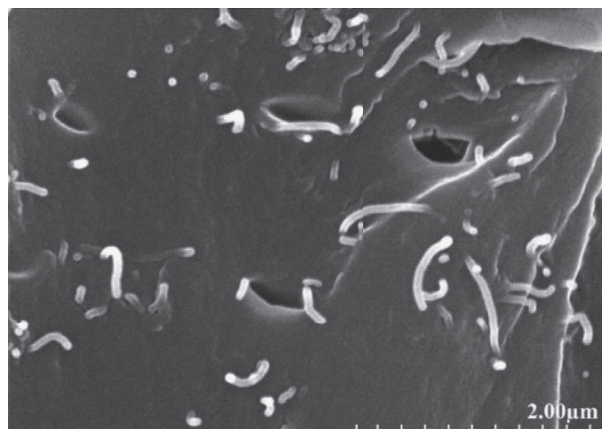

(c)

Figure 6: SEM images of nanocomposites fly ash/MWCNTs/epoxy: (a) 40 wt.\% fly ash/0.04 wt.\% MWCNTs/epoxy; (b) 40 wt.\% fly ash/0.03 wt.\% MWCNTs/epoxy; and (c) 40 wt.\% fly ash/0.05 wt.\% MWCNTs/epoxy.

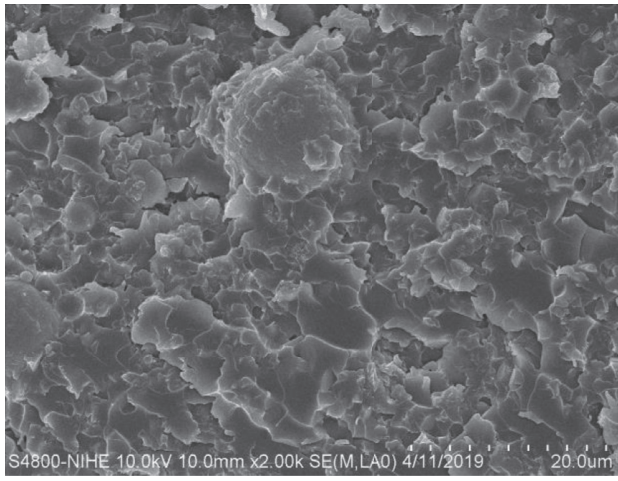

(a)

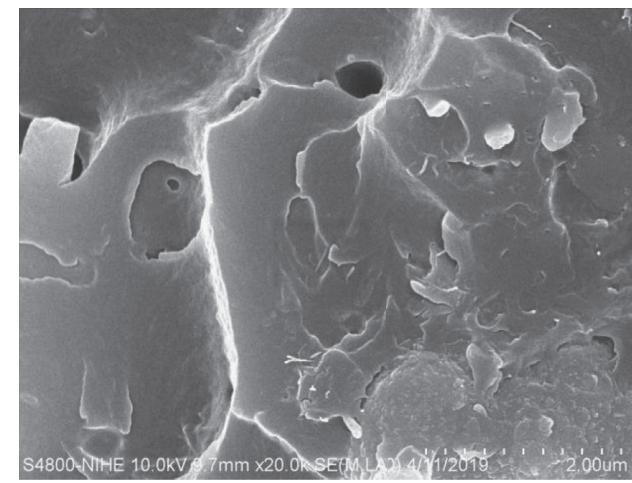

(b)

FIGURE 7: SEM images of nanocomposites fly ash/MWCNTs/epoxy: 40 wt.\% fly ash/0.04 wt.\%/epoxy.

prevented, and cracks change direction when they pass over the point where MWCNTs are present. As a result, cracks begin to become difficult to develop.

From the table of results of mechanical properties, the tensile strength compared with the results of Sroka et al. published was almost similar. In the work of Sroka et al. $[3,4]$, fly ash was modified, while in this work, the interwoven structure of nano additives (MWCNTs) increased material sustainable cooporation and had reinforcing role for materials. The mechanical properties have been improved and still ensure the tensile strength is kept at the prescribed level.
3.3. Fire Retardant Properties. If a layer of ash can be formed during the combustion of polymers, it can act as an insulating sheet, limiting heat transfer from the source to the polymers. Therefore, the number and texture of ash layers is important to limit the combustion of polymers.

Fly ash flame retardants and MWCNTs are dispersed in epoxy resins to enhance the flame retardant properties of epoxy resins. The results of fire resistance assessment of the fly ash/MWCNTs combination for epoxy are shown in Table 4.

From Table 4, it was found that the best results were a combination of $0.04 \%$ by weight of MWCNTs and $40 \%$ by weight of fly ash, LOI index of $26.8 \%$, combustion rate of 
TABLe 3: Optimum mechanical properties of epoxy/fly ash/MWNT nanocomposites from fine tuning experiments.

\begin{tabular}{|c|c|c|c|c|c|c|c|}
\hline Trial & $\begin{array}{l}\text { Sample } \\
\text { code }\end{array}$ & $\begin{array}{c}\text { Fly ash content } \\
(\mathrm{wt} \%)\end{array}$ & $\begin{array}{c}\text { MWCNTs content } \\
(\mathrm{wt} \%)\end{array}$ & $\begin{array}{l}\text { Tensile strength } \\
(\mathrm{MPa})\end{array}$ & $\begin{array}{c}\text { Flexural strength } \\
(\mathrm{MPa})\end{array}$ & $\begin{array}{c}\text { Compressive strength } \\
(\mathrm{MPa})\end{array}$ & $\begin{array}{c}\text { Impact strength } \\
\left(\mathrm{kJ} / \mathrm{m}^{2}\right)\end{array}$ \\
\hline 1 & Epoxy & 0.00 & 0.00 & 55.90 & 86.75 & 156.08 & 7.11 \\
\hline 2 & FA01 & 0.00 & 0.03 & 65.89 & 91.37 & 189.39 & 10.07 \\
\hline 3 & FA02 & 30 & 0.00 & 39.47 & 60.08 & 165.12 & 5.90 \\
\hline 4 & FAST1 & 30 & 0.03 & 52.50 & 77.09 & 170.00 & 6.50 \\
\hline 5 & FAST2 & 40 & 0.03 & 50.04 & 72.10 & 173.25 & 7.90 \\
\hline 6 & FAST3 & 50 & 0.03 & 44.44 & 68.25 & 175.05 & 8.80 \\
\hline 7 & FAST4 & 30 & 0.04 & 59.03 & 78.55 & 188.89 & 10.75 \\
\hline 8 & FAST5 & 40 & 0.04 & 58.79 & 79.39 & 225.09 & 16.09 \\
\hline 9 & FAST6 & 50 & 0.04 & 47.02 & 71.19 & 220.21 & 14.68 \\
\hline 10 & FAST7 & 30 & 0.05 & 56.15 & 76.97 & 218.09 & 14.87 \\
\hline 11 & FAST8 & 40 & 0.05 & 54.12 & 73.60 & 223.09 & 16.37 \\
\hline 12 & FAST9 & 50 & 0.05 & 49.60 & 71.77 & 229.88 & 15.76 \\
\hline
\end{tabular}

The bold values indicate that at the fabrication rate of 40 percent by weight of fly ash combined with 0.04 percent by weight of MWCNTs, the mechanical properties of the material are improved more than the others.

TABLE 4: Results for flammability tests (reaction to small flame) oxygen index (OI) and UL 94 for fly ash/MWCNTs/epoxy nanocomposites.

\begin{tabular}{|c|c|c|c|c|c|c|}
\hline Trial & Material & Fly ash content (wt\%) & $\begin{array}{c}\text { MWCNTs content } \\
\text { (wt } \%)\end{array}$ & LOI $(\operatorname{vol} \% \mathrm{O} 2 \pm 2 \sigma)$ & Combustion rate $(\mathrm{mm} / \mathrm{min})$ & UL94 HB ( $\mathrm{mm} / \mathrm{min})$ \\
\hline 1 & Epoxy & 0.00 & 0.00 & 20.6 & 28.41 & Not rated (NR) \\
\hline 2 & FA01 & 0.00 & 0.03 & 21.9 & 24.90 & $21.76(\mathrm{HB})$ \\
\hline 3 & FA02 & 30 & 0.00 & 21.5 & 26.12 & $22.08(\mathrm{HB})$ \\
\hline 4 & FAST1 & 30 & 0.03 & 23.7 & 25.21 & $20.87(\mathrm{HB})$ \\
\hline 5 & FAST2 & 40 & 0.03 & 24.1 & 22.05 & $18.55(\mathrm{HB})$ \\
\hline 6 & FAST3 & 50 & 0.03 & 25.0 & 21.44 & $17.71(\mathrm{HB})$ \\
\hline 7 & FAST4 & 30 & 0.04 & 25.4 & 18.45 & $16.45(\mathrm{HB})$ \\
\hline 8 & FAST5 & 40 & 0.04 & 26.8 & 16.05 & $15.67(\mathrm{HB})$ \\
\hline 9 & FAST6 & 50 & 0.04 & 26.3 & 15.34 & $15.05(\mathrm{HB})$ \\
\hline 10 & FAST7 & 30 & 0.05 & 26.3 & 17.32 & $17.67(\mathrm{HB})$ \\
\hline 11 & FAST8 & 40 & 0.05 & 26.8 & 16.47 & $16.79(\mathrm{HB})$ \\
\hline 12 & FAST9 & 50 & 0.05 & 26.3 & 27.81 & $18.09(\mathrm{HB})$ \\
\hline
\end{tabular}

The bold values indicate that at the manufacturing rate of 40 percent by weight of fly ash combined with 0.04 percent by weight of MWCNTs, the flame retardant properties of the material are improved more than other rates.

$16.05 \mathrm{~mm} /$ minute, and combustion rate with UL. $94 \mathrm{HB}$ reaches $15.67 \mathrm{~mm} /$ minute.

A layer of coal (ash) is spread evenly keeping the sample without the drip and improved the flame resistance of epoxy. The combination of fire protection mechanisms has improved the fire resistance of the material.

When MWCNTs are well dispersed in the substrate, the created coal layer will cover more evenly on the surface. And this shield will minimize the ability ignition as well as exposure to air oxygen. At the same time, it reduces the tendency to catch fire again, making the fire unable to spread and extinguish. It can be seen that the more uniform the distribution of fire retardant additives in the substrate, the greater the fire resistance and mechanical properties of nanocomposite are improved.

A layer of residue generated from MWCNTs and fly ash on the sample surface during combustion is very important, acting as a heat shield and preventing heat spread. It may delay the transfer of heat from the flame, resulting in a slower increase in temperature. It can be said that MWCNTs and fly ash have synergized to increase the high fire resistance of composites; these are environmentally friendly flame retardants that promise great applicability in life.

This was confirmed by the qualitative investigation by FESEM, which revealed the presence and dispersion of some relatively large MWCNT agglomerates, as shown in Figure 7. The fracture surface shows a typical brittle failure in between the nanotubes and epoxy resin. This indicates that the strong adhesion takes place in between MWCNT-epoxy resin and fractured in different planes. When the loading increases, the cracks will form in the weak area of the MWCNT network.

The multiwalled carbon nanotubes play an important role in pinning crack (Figure 8(b)) and carry more external force (the crack (red arrow) is blocked by nanoparticles). They have a firm connection and strong interaction with the matrix. So, the carbon nanotubes, effectively, prevent the expansion of microcracks resulting from the stress concentration and improve the strength of composites.

Multiwalled carbon nanotube increases the performance of pure epoxy resin because of resisting the deformation of matrix. However, uniform dispersion and perfect adhesion of MWCNTs in the epoxy resin is the main reason to increase the mechanical properties of epoxy resin. Therefore, the mechanical properties and flame retardant of nanocomposite materials ( $40 \%$ by weight of fly ash, $0.04 \%$ by weight of MWCNTs) achieved better value than the other samples.

When increasing the percentage of fly ash to 50 parts by weight, the fire retardation tends to decrease. At this ratio the 


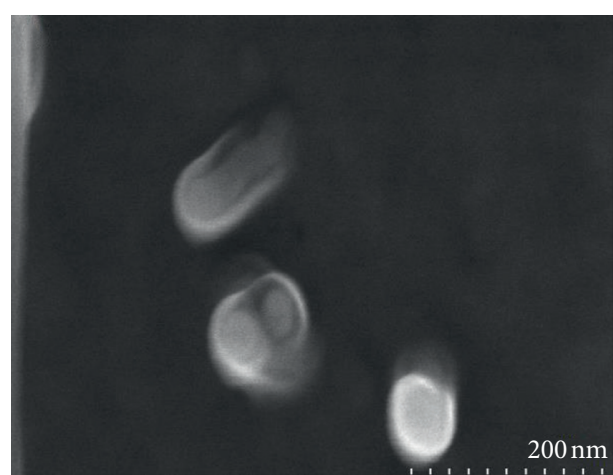

(a)

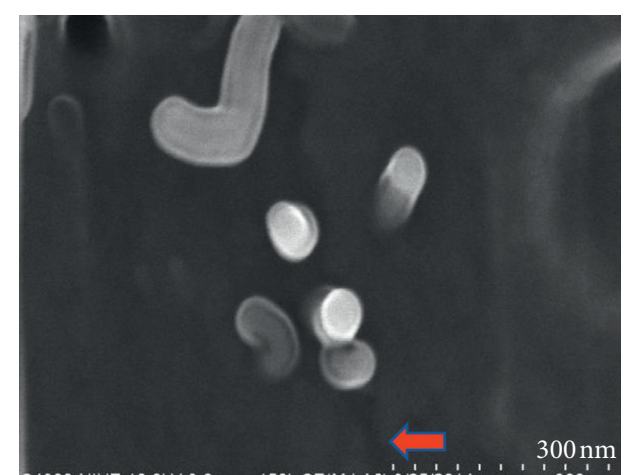

(b)

FIGURE 8: FE-SEM images of nanocomposites fly ash/MWCNTs/epoxy: 40 wt.\% fly ash/0.04 wt.\% MWCNTs/epoxy ((a), (b)).

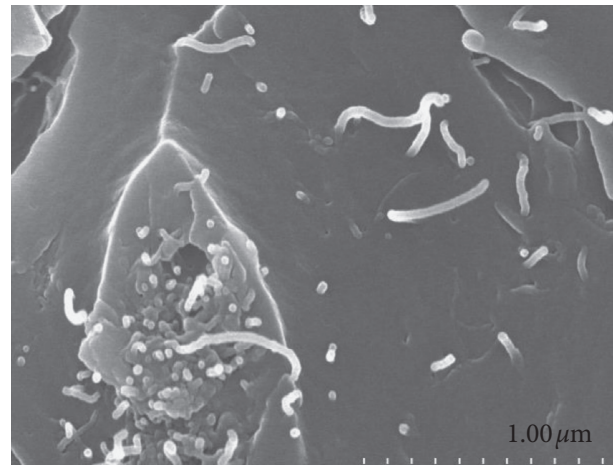

(a)

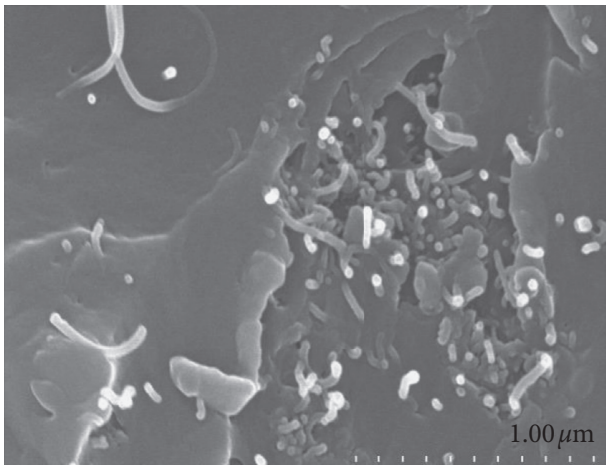

(b)

Figure 9: FE-SEM images of nanocomposites: (a) fly ash/MWCNTs/epoxy: 50 wt.\% fly ash/0.03 wt.\% MWCNTs/epoxy and (b) fly ash/ MWCNTs/epoxy: 50 wt.\% fly ash/0.05 wt.\% MWCNTs/epoxy.
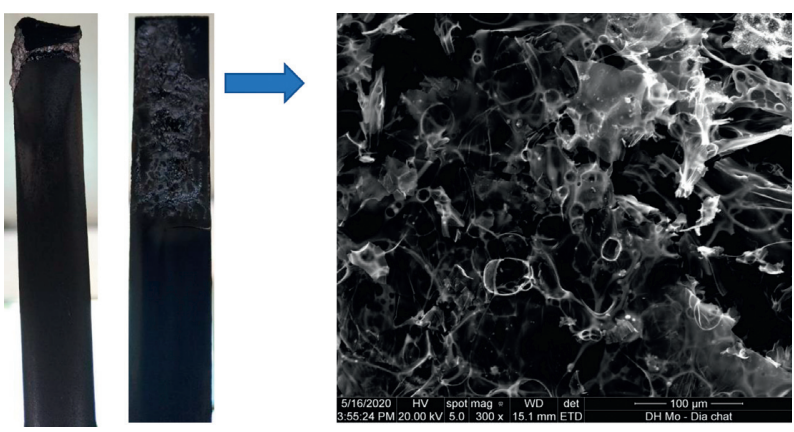

FIGURE 10: SEM morphologies of the residua of nanocomposites fly ash/MWCNTs/epoxy: 40 wt.\% fly ash/0.04 wt.\% from ignition by alcohol burner (UL 94HB).

compatibility between fly ash and MWCNTs decreases, because then the viscosity of the mixture increases due to fly ash. Therefore, the dispersion ability of MWCNTs will be more difficult. The agglomeration as well as poor dispersion ability of MWCNTs will seriously affect the fireproof properties as well as the mechanical properties (see Figures 9(a) and 9(b)).

Extraordinarily, the residual char of nanocomposite (Figure 10) was very dense and continuous; no holes could be found. This was determined by the dispersion states of CNTs in the residues. In the char of nanocomposite (Figure 10), a lot of MWCNTs aggregates could be found. This implies that MWCNTs reaggregated during combustion.

From the results of Table 4 , the role of nanoadditives (MWCNTs) in the fire resistance of materials is clearly recognized. Compared to the results published by Divya et al. [7], the trend is the same rule despite different background studies. Divya et al. published that 0.2 wt.\% 
MWCNTs combined with 20 wt.\% fly ash is the optimal value. In this work, meanwhile, the optimal ratio is $0.04 \mathrm{wt} \%$ MWCNTs combined with 40 wt.\% fly ash.

\section{Conclusions}

We found that fly ash, which is a byproduct of thermal power plants, greatly enhanced the fire resistance of epoxy and thus reduced the amount of energy needed to produce flame retardant epoxy. Adding a large amount of fly ash (40 wt.\%) reduces the mechanical properties and molding capabilities of the material. However, the fire retardation is enhanced and the mechanical properties are significantly improved due to the presence of MWCNTs with 0.04 wt.\%. The results of structural morphology (SEM) showed that fly ash mixed with epoxy at high content (30, 40, and $50 \mathrm{wt} . \%)$ had good compatibility with the substrate even in the presence of nanoadditives (MWCNTs), thus promising the future environmentally friendly green composites with many practical applications.

In this work, the surface of fly ash has not been modified so the compatibility with the base resin is not strong compared with what has been observed in previous works $[2,3]$. However, due to the synergies between unmodified fly ash and multiwalled carbon nanotubes (MWCNTs) at an appropriate fabrication rate, the manufacturing materials ensure mechanical properties and fire retardation at the prescribed level. Nanocomposite materials can be applied in industrial consumer electronics and construction materials with high fire resistance.

\section{Data Availability}

The data used to support the findings of this study are included within the article.

\section{Conflicts of Interest}

The authors declare that there are no conflicts of interest regarding the publication of this paper

\section{Acknowledgments}

The authors wish to thank the Faculty of Chemical Technology, Hanoi University of Industry, for funding this work.

\section{References}

[1] A. A. Jumaat, N. F. Afandi, A. Manap, R. A. Zainuddin, S. Mahalingam, and N. F. Abd Kadir, "Synthesis of multiwall carbon nanotube with fly ash in the production of desired green concrete," Journal of Physics: Conference Series, vol. 1349, Article ID 012021, 2019.

[2] M. Singla and V. Chawla, "Mechanical properties of epoxy resin-fly ash composite," Journal of Minerals and Materials Characterization and Engineering, vol. 9, no. 3, pp. 199-210, 2010.

[3] J. Sroka, A. Rybak, R. Sekula et al., "An investigation into the influence of filler silanization conditions on mechanical and thermal parameters of epoxy resin-fly ash composites,"
Journal of Polymers and the Environment, vol. 24, no. 4, pp. 298-308, 2016.

[4] J. Sroka, A. Rybak, R. Sekula et al., "Two-step procedure of fly ash modification as an alternative method for creation of functional composite," Journal of Polymers and the Environment, vol. 25, no. 4, pp. 1342-1347, 2016.

[5] T. Chaowasakoo and N. Sombatsompop, "Mechanical and morphological properties of fly ash/epoxy composites using conventional thermal and microwave curing methods," Composites Science and Technology, vol. 67, no. 11-12, pp. 2282-2291, 2007.

[6] T. A. Nguyen, Q. T. Nguyen, T. P. Bach, and V. H. Nguyen, "Study on fire resistance ability and mechanical properties of composites based on epikote 240 epoxy resin and thermoelectric fly ash: an ecofriendly additive," Journal of Chemistry, vol. 2019, Article ID 2635231, 8 pages, 2019.

[7] V. C. Divya, M. A. Khan, B. N. Rao, R. R. N. Sailaja, and S. Vynatheya, "Fire retardancy characteristics and mechanical properties of high-density polyethylene/ultrafine fly ash/ MWCNT nanocomposites," Polymer-Plastics Technology and Engineering, vol. 56, no. 7, pp. 762-776, 2016.

[8] M. Soyama, K. Inoue, and M. Iji, "Flame retardancy of polycarbonate enhanced by adding fly ash," Polymers for Advanced Technologies, vol. 18, no. 5, pp. 386-391, 2007.

[9] J. Sim, Y. Kang, B. J. Kim, Y. Ho Park, and Y. C. Lee, "Preparation of fly ash/epoxy composites and its effects on mechanical properties," Polymers, vol. 12, no. 79, pp. 1-12, 2020.

[10] A. Pattanaik, M. Mukharjee, and S. C. Mishra, "Effect of environmental aging conditions on the properties of fly ash filled epoxy composites," Advanced Composite Materia, vol. 29, no. 1, pp. 1-30, 2020.

[11] P. Bachtrong, L. Nguyenthanh, and H. Phamthi, "Effect of fly ash from thermal power plant on the dielectric properties of polymer composites materials based on matrix epoxy DER 331," Chemical Engineering Transactions, vol. 56, pp. 12071212, 2017.

[12] P. Rovnaník, H. Šimonová, L. Topolář, P. Schmid, and Z. Keršner, "Effect of carbon nanotubes on the mechanical fracture properties of fly ash geopolymer," Procedia Engineering, vol. 151 , pp. 321-328, 2016.

[13] M. Saafi, K. Andrew, P. L. Tang et al., "Multifunctional properties of carbon nanotube/fly ash geopolymeric nanocomposites," Construction and Building Materials, vol. 49, pp. 46-55, 2013.

[14] T. A. Nguyen, "Effects of the amount of fly ash modified by stearic acid compound on mechanical properties, flame retardant ability, and structure of the composites," International Journal of Chemical Engineering, vol. 2020, Article ID 2353827, 8 pages, 2020.

[15] T. A. Nguyen, "Effects of the amount of fly ash modified by stearic acid compound on mechanical properties, flame retardant ability, and structure of the composites," International Journal of Chemical Engineering, vol. 2020, Article ID 2079189, 6 pages, 2020. 